\title{
Assessment of Knowledge of Cervical Cancer Transmission and Prevention among the Mothers of Daughters Aged Below 10 Years
}

\section{Khan $\mathrm{SZ}^{1 *}$, Haseen $\mathrm{F}^{2}$ and Islam SS ${ }^{2}$}

${ }^{1}$ Department of Community Medicine, Green Life Medical College, Bangladesh

${ }^{2}$ Department of Public Health \& Informatics, Bangabandhu Sheikh Mujib Medical University, Bangladesh

*Corresponding author: Sharmin Zaman Khan, Department of Community Medicine, Green Life Medical College, Dhaka, Bangladesh, Email: sharminkhan@rocketmail.com

\section{Research Article}

Volume 5 Issue 2

Received Date: July 12, 2021

Published Date: August 13, 2021

DOI: $10.23880 /$ whsj-16000161

\section{Abstract}

Introduction: Cervical Cancer is the second most common cancer among women worldwide. It is one of the few preventable human cancers. Maternal knowledge is required for vaccination of their adolescent girls because they are key decision makers and potentially a major source of information for their daughters. Bangladesh Government will introduce HPV vaccine under EPI program for adolescent girls aged 10 years from 2018. For this reason, it is important to assess the knowledge level of mothers of daughters aged below 10 years.

Objective: The objective of this study was to assess the knowledge of Cervical Cancer transmission, prevention and HPV vaccine among mothers of daughters aged below 10 years.

Methods: A cross sectional descriptive study has been conducted among the mothers of daughters aged below 10 years, live in the Mohakhali 'Sat Tola' slum area of Dhaka city. The pre-tested questionnaire was used to collect information from the respondents by face to face interview at house-hold level. Questions were on socio-demographic characteristics, knowledge about Cervical Cancer transmission, prevention and HPV vaccination. Convenient sampling technique was used to select the sample. The sample size was 100 in number. The total no. of questions on knowledge was 22. Knowledge score was divided into 3 categories: poor, average and good knowledge. Poor knowledge score was 0 to 7, average knowledge score was 8 to 14 and good knowledge score was 15 to 22. Frequency, percentage and mean was done by using SPSS version 21.

Results: Majority (41\%) respondents' age was 21 to 29 years, most (63\%) of them were primary school educated, most (80\%) of them were house-wife and most (43\%) of their monthly family income was 11,000 to 15,000 taka. Respondent's mean age at marriage was 15 years and mean age was 17 years when their first child born, majority (39\%) had two children. In total, $55 \%$ respondents had poor knowledge, $45 \%$ respondents had average knowledge and $2 \%$ respondents had good knowledge. Among them $98 \%$ respondents heard about cancer, $77 \%$ respondents heard about Cervical Cancer, $8 \%$ respondents knew about sign and symptom and only $2 \%$ respondents knew the causes of Cervical Cancer, $3 \%$ respondents told prevention of Cervical Cancer is possible but $12 \%$ respondents heard about VIA test. Around $18 \%$ respondents heard about HPV vaccine but nobody knew in which age this vaccine should be administered.

Conclusion: The knowledge of Cervical Cancer transmission, prevention and HPV vaccination among mothers who live in slum of Dhaka city is poor. Providing knowledge to these mothers is essential. 


\section{Women's Health Science Journal}

Keywords: Cervical Cancer; Transmission; Prevention; HPV vaccine; Human Papilloma Virus

Abbreviations: WHO: World Health Organization; HPV: Human Papilloma Virus.

\section{Introduction}

Cervical Cancer is one of the few preventable human cancers [1]. It is the second most common cancer among women worldwide and about $86 \%$ of Cervical Cancer occurs in developing countries [2]. More than half a million women are newly diagnosed with Cervical Cancer each year, with approximately $90 \%$ of Cervical Cancer-related death occurring in developing countries [3]. However, in developing countries, it remains the most common cause of cancer related deaths among women. Cervical Cancer which is one of the preventable cancers and the important public health problem worldwide and especially in developing countries [4].

There are 13 to 15 lakh cancer patients in Bangladesh, with about 2 lakh patients newly diagnosed with cancer each year. As an overview, in women, Cervical Cancer and breast cancer are most prevalent [5]. According to World Health Organization (WHO) statistics, incidence of Cervical Cancer cases in Bangladesh has been estimated at 167 per 100,000 populations and 6,582 women die every year in the country for this cancer. The problem of Cervical Cancer in Bangladesh is particularly acute because of poverty, early age marriage, multiple marriages, high parity and illiteracy. In developing countries, women's knowledge about risk factors of Cervical Cancer is very limited. However, it is considered one of the most preventable cancers [6].

Despite the high prevalence of Cervical Cancer, many studies have shown that women's knowledge about HPV and Cervical Cancer is very low [1]. The incidence of Human Papilloma Virus (HPV) infection and Cervical Cancer can be reduced by increasing vaccination for HPV [7]. In Bangladesh, there is little awareness among the general population, health care professionals and policy makers about Cervical Cancer prevention. Immunization against the most prevalent HPV types affecting the country may be an efficient means to long term prevention [8]. Maternal knowledge is required for vaccination of adolescent girls; they are key decision makers and potentially a major source of information for their daughters [9]. Therefore, improving the knowledge of the mothers who have daughters aged below 10 years regarding Cervical Cancer transmission, prevention and organism is one of the most important steps in enhancing the vaccination coverage among Bangladeshi females. The objective of this study was to determine the knowledge of Cervical Cancer transmission, prevention and organism among the mothers of selected slum area of Dhaka city to identify the main barrier to get information about Cervical Cancer, so that possible interventions could be taken to increase the level of knowledge of Cervical Cancer of mothers.

\section{Methods}

This was a cross-sectional descriptive study design. This study was done in 'Sat Tola' slum in Mohakhali, Dhaka, Bangladesh. The study was conducted from January, 2016 to December, 2016. Data collection was done for four weeks. Population was the mothers of daughters aged below 10 years, were defined as study population. Mothers who have daughters aged below 10 years were taken because; Cervical Cancer vaccine is given between 12 years to 18 years. So, before 10 years if a mother know about Cervical Cancer and its vaccine then she can take her daughters for vaccine for Cervical Cancer prevention. The mothers were selected by using convenient sampling technique. The mothers who gave voluntary consent were taken as sample. Inclusion criteria are mothers who have daughters aged below 10 years and mothers who are willing to participate in the study. Sample size was 100; pre-tested questionnaire was used to collect information from the respondents by face to face interview at house hold level. This study used a questionnaire, consists of 22 questions about knowledge of Cervical Cancer, Cervical Cancer transmission, prevention and HPV. Among the questions 7 questions about knowledge of Cervical Cancer and Cervical Cancer transmission, 11 questions about knowledge of Cervical Cancer prevention and 4 questions about knowledge of HPV. Each question was scored '1' point for the correct response and ' 0 ' for the wrong answer. An overall total knowledge score was calculated by adding up the correct score of each respondent across all 22 questions. Knowledge score was divided into 3 categories which is poor, average and good knowledge. Statistical data analysis was done using SPSS software version 21.0.

\section{Results}

In Table 1 shown, 41\% respondents' age was between 21-29 years, $63 \%$ were primary school educated, $80 \%$ were house-wife, $43 \%$ respondents' monthly family income was $11,000-15,000$ taka, mean age at marriage was $14.62 \pm 2.673$ years, mean age during first child born was $17.13 \pm 2.866$ years, 39\% respondent had two children, mean age of last child was $63.4 \pm 39.92$ months and mean knowledge score was 7.19 out of 22 . 


\begin{tabular}{|c|c|c|}
\hline Socio-demographic characteristics & Frequency(n) & Percentage (\%) \\
\hline \multicolumn{3}{|c|}{ A. Age of respondents in year } \\
\hline$<20$ & 17 & $17 \%$ \\
\hline $21-29$ & 41 & $41 \%$ \\
\hline $30-39$ & 30 & $30 \%$ \\
\hline 40 and above & 11 & $11 \%$ \\
\hline Don't know & 1 & $1 \%$ \\
\hline \multicolumn{3}{|c|}{ Mean age of respondents in year \pm SD $29.08 \pm 9.621$} \\
\hline \multicolumn{3}{|c|}{ B. Educational status } \\
\hline No formal education & 33 & $33 \%$ \\
\hline Primary & 63 & $63 \%$ \\
\hline Secondary and above & 4 & $4 \%$ \\
\hline \multicolumn{3}{|c|}{ C. Employment status } \\
\hline House wife & 80 & $80 \%$ \\
\hline Service holder & 10 & $10 \%$ \\
\hline Business & 2 & $2 \%$ \\
\hline Maid servant & 8 & $8 \%$ \\
\hline \multicolumn{3}{|c|}{ D. Monthly house-hold income in taka } \\
\hline$<5000$ & 15 & $15 \%$ \\
\hline $6,000-10,000$ & 38 & $38 \%$ \\
\hline $11,000-15,000$ & 43 & $43 \%$ \\
\hline$>15,000$ & 4 & $4 \%$ \\
\hline \multicolumn{3}{|c|}{ E. Age at marriage of respondents in year (mean \pm SD) $14.62 \pm 2.673$} \\
\hline \multicolumn{3}{|c|}{ F. Age during first child born in year (mean \pm SD) $17.13 \pm 2.866$} \\
\hline \multicolumn{3}{|c|}{ G. Number of children of respondents } \\
\hline One & 28 & $28 \%$ \\
\hline Two & 39 & $39 \%$ \\
\hline Three & 17 & $17 \%$ \\
\hline Four & 8 & $8 \%$ \\
\hline Five or more than five & 8 & $8 \%$ \\
\hline \multicolumn{3}{|c|}{ H. Age of last child in month (mean \pm SD) $63.4 \pm 39.92$} \\
\hline \multicolumn{3}{|c|}{ I. Knowledge score (mean) 7.19 out of 22} \\
\hline
\end{tabular}

Table 1: Distribution of respondents by socio-demographic characteristics ( $n=100)$.

In Table 2 shown, 98\% respondents heard about Cancer but only $77 \%$ mothers heard about Cervical Cancer where $54.9 \%$ respondents heard from neighbor. Only $8 \%$ respondents had knowledge about sign symptom and only $2 \%$ respondents had knowledge about causes of Cervical Cancer. 


\begin{tabular}{|c|c|c|}
\hline Variables & Frequency (n) & Percentage (\%) \\
\hline \multicolumn{3}{|c|}{ A. Heard about Cancer } \\
\hline Yes & 98 & $98 \%$ \\
\hline No & 2 & $2 \%$ \\
\hline \multicolumn{3}{|c|}{ B. Heard about Cervical Cancer } \\
\hline Yes & 77 & $77 \%$ \\
\hline No & 23 & $23 \%$ \\
\hline \multicolumn{3}{|c|}{ C. Sources of knowledge about Cervical Cancer $(n=77)$} \\
\hline Health worker & 14 & $17.10 \%$ \\
\hline Television & 10 & $12.20 \%$ \\
\hline Neighbor & 45 & $54.90 \%$ \\
\hline Relatives & 13 & $15.90 \%$ \\
\hline \multicolumn{3}{|c|}{ D. Knowledge about sign symptom of Cervical Cancer $(\mathrm{N}=100)$} \\
\hline Yes & 8 & $8 \%$ \\
\hline No & 92 & $92 \%$ \\
\hline \multicolumn{3}{|c|}{ E. Knowledge about causes of Cervical Cancer $(\mathrm{N}=100)$} \\
\hline Yes & 2 & $2 \%$ \\
\hline No & 92 & $92 \%$ \\
\hline
\end{tabular}

Table 2: Knowledge about Cervical Cancer transmission ( $\mathrm{N}=100)$.

\begin{tabular}{|c|c|c|}
\hline Variables & Frequency (n) & Percentage (\%) \\
\hline \multicolumn{3}{|c|}{ A. Heard about VIA test } \\
\hline Yes & 12 & $12 \%$ \\
\hline No & 88 & $88 \%$ \\
\hline \multicolumn{3}{|c|}{ B. Checkup Cervix by VIA test } \\
\hline Yes & 3 & $3 \%$ \\
\hline No & 97 & $97 \%$ \\
\hline \multicolumn{3}{|c|}{ C. Heard about Cervical Cancer vaccine } \\
\hline Yes & 18 & $18 \%$ \\
\hline No & 82 & $82 \%$ \\
\hline \multicolumn{3}{|c|}{ D. Source of knowledge about Cervical Cancer vaccine $(n=18)$} \\
\hline Health worker & 10 & $55.60 \%$ \\
\hline Television & 1 & $5.60 \%$ \\
\hline Neighbor & 5 & $27.80 \%$ \\
\hline Relative & 2 & $11.10 \%$ \\
\hline \multicolumn{3}{|c|}{ E. Receive Cervical Cancer vaccine } \\
\hline Yes & 2 & $2 \%$ \\
\hline No & 98 & $98 \%$ \\
\hline \multicolumn{3}{|c|}{ F. Heard about Human Papilloma Virus } \\
\hline Yes & 6 & $6 \%$ \\
\hline No & 94 & $94 \%$ \\
\hline \multicolumn{3}{|c|}{ G. Knowledge about age of Cervical Cancer vaccine } \\
\hline Yes & 0 & $0 \%$ \\
\hline No & 100 & $100 \%$ \\
\hline
\end{tabular}

Table 3: Knowledge about Cervical Cancer prevention and organism ( $\mathrm{N}=100)$. 
In Table 3 shown, $12 \%$ respondents heard about VIA test, only $3 \%$ checkup Cervix by VIA test, $18 \%$ respondents heard about Cervical Cancer vaccine. Among them 55.6\% heard from health worker. Only $2 \%$ respondents took vaccine only 6\% heard about Human Papilloma Virus and 100\% respondents did not know in which age vaccine should be administered.

In Figure 1 shown, 60\% respondents did not know whether Cervical Cancer prevention is possible or not, 36\% told prevention is possible and $4 \%$ told prevention is not possible.

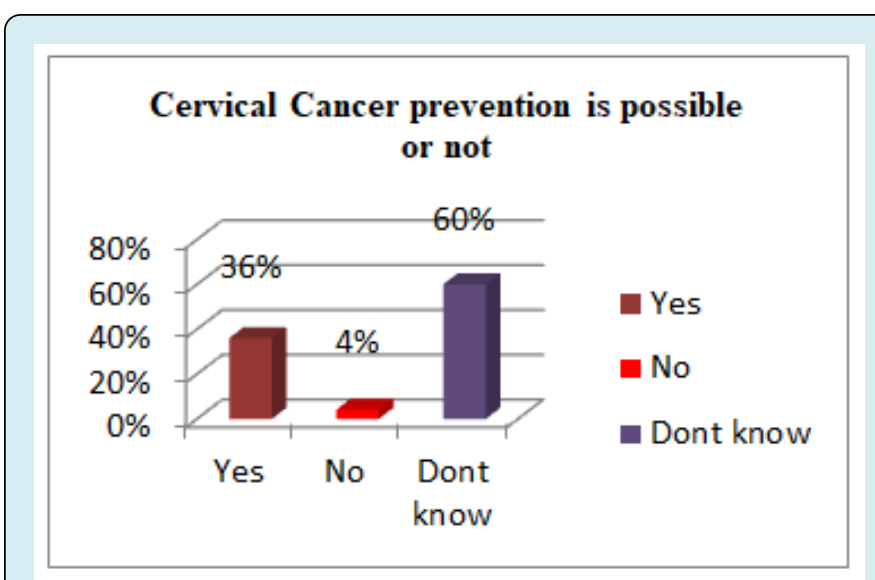

Figure 1: Opinion about prevention of Cervical Cancer.

In Figure 2 shown, 87 respondents wanted to know about Cervical Cancer from health worker, 12 respondents from hospital and 7 respondents from television.

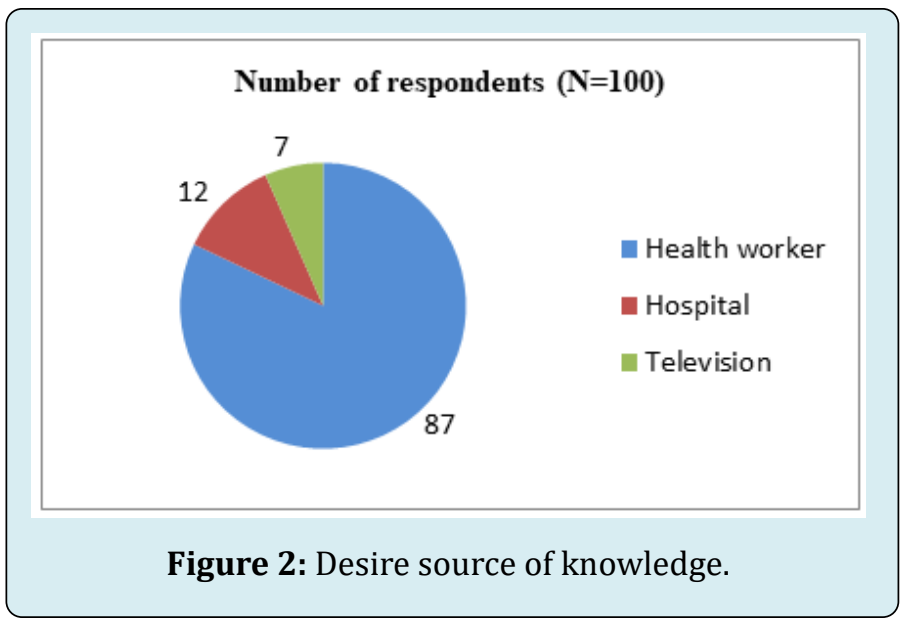

In Figure 3 shown, 55\% respondents had poor knowledge, $43 \%$ had average knowledge and only $2 \%$ had good knowledge.

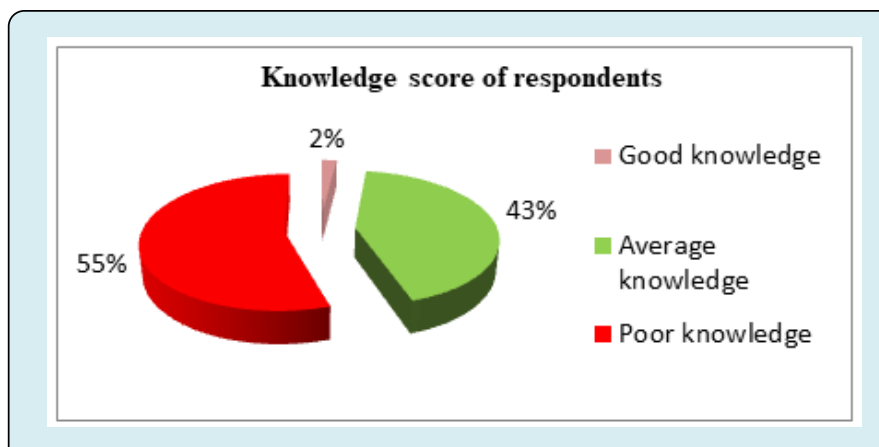

Figure 3: Knowledge score of respondents $(n=100)$.

\section{Discussion}

Knowledge on Cervical Cancer among different groups, professionals, populations and students were evaluated by survey worldwide in several studies. In Bangladesh, socioepidemiological data on Cervical Cancer status are scarce, particularly Cervical Cancer knowledge of mothers. The mean age of the study subjects was $29.08 \pm 9.621$ years. In a study conducted by Fernandez, et al. it was seen that mothers' mean age was $47.9 \pm 5.5$ years. In our study, $63 \%$ mothers had primary education, $3 \%$ mothers had secondary and $1 \%$ mothers had higher secondary education. In a study conducted by Kose, et al. [4], 63\% of the mothers were primary school, $25.7 \%$ were high school and $11.4 \%$ were university graduates. In this study, it was found out that $77 \%$ mothers heard of Cervical Cancer. In a study conducted by Ahmed, et al. [10], it was seen that $66.9 \%$ of the mothers had heard of Cervical Cancer. In our study, only $2 \%$ mothers knew about causes of Cervical Cancer where in a study, conducted at Nigeria by Ahmed, et al. [10], it was seen that $62.5 \%$ mothers knew about causes of Cervical Cancer. In our study, $12 \%$ mothers heard about VIA test and 18\% mothers heard about HPV vaccine. In other studies conducted it is seen that $83.5 \%$ of the mothers 4 and $53.7 \%$ of the mothers [11] had no knowledge about HPV vaccination. Among 18 mothers who expressed that they knew about vaccination, $55.6 \%(n=10)$ stated that they learned about it from a health worker, $27.8 \%$ $(n=5)$ of them learned it from neighbor, $11.1 \%(n=2)$ learned it from relative and $5.6 \%(n=1)$ learned it from television. In a study conducted by Kose, et al. [4], 27.1\% ( $n=35)$ stated that they learned about it from a health professional, $61.2 \%$ $(n=79)$ of them learned it from communication tools like television, radio, newspapers or internet, $11.6 \%(\mathrm{n}=15)$ learned it from friends or relatives. In our study, only $2 \%$ $(n=2)$ mothers took HPV vaccine, $100 \%(n=100)$ among 100 mothers did not know the age of HPV vaccine administration. In a study conducted by Kose, et al. [4], found out that a total of $0.7 \%$ mothers who had daughters were found out to be vaccinated against HPV, $83.2 \%$ of the mothers did not know age of vaccination was applied. In our study, it was seen that $94 \%$ of the mothers who have daughters aged below 10 


\section{Women's Health Science Journal}

years had never heard of HPV before. In a study conducted by Marlow, et al. [12], it was seen that HPV knowledge $72.8 \%$ of the mothers who have daughters between the ages of 8-14 had never heard of HPV before. In our study the knowledge score of Cervical Cancer showed that there was good knowledge $(2 \%)$ about Cervical Cancer among the mothers, living in slum area. Study conducted by Ahmed, et al. where the knowledge score of Cervical Cancer showed that there was a fair knowledge (43.5\%) of Cervical Cancer among respondents living in slum area. In this study there was no significant association between mothers' education level and their knowledge score. In a similar study conducted by Ozan, et al. [13], there was no significant difference. However, in a similar study conducted by Kose, et al. [4], there was a significant association between the mothers' education level and their knowledge. According to mothers' economic conditions, there is no significant association between their knowledge about HPV and economic condition. However, there was a significant relationship between high income and the mothers' awareness of HPV was found by Sanders Thompson, et al. [14].

\section{Conclusion and Recommendation}

This study showed that most of the respondents heard about Cancer and Cervical Cancer, among mothers who heard about Cervical Cancer most of them heard from neighbor. But most of the respondents did not know about sign symptoms and the causes of Cervical Cancer. Majority of the respondents did not know whether Cervical Cancer prevention is possible or not. In this study, study was done on mothers who have daughters aged below 10 years at slum area of Dhaka city where under-privileged people lived, they are deprived from health services such as home visit from female health worker from government sector that's why the mothers cannot get proper information about health so if we want to increase the knowledge level of mothers living in a slum area of Dhaka city at first we have to provide information to increase awareness among mothers about Cervical Cancer, Cervical Cancer transmission, prevention and HPV. The mothers who had some information about Cervical Cancer stated that they learned about the subject from neighbor, health worker, relatives and television. Based on this result, it can be suggested that doctors and nurses should be informed about this situation. Despite low knowledge of Cervical Cancer, all mothers were willing to get information about this disease, where majority of them wanted to get information from health worker. We recommend improving mothers' knowledge through health education.

\section{References}

1. Assoumou SZ, Mabika BM, Mbiguino AN, Mouallif M, Khattabi A, et al. (2015) Awareness and knowledge regarding of Cervical Cancer, pap smear screening and Human Papilloma Virus infection in Gabonese women. Journal of Negative Results in Biomedicine 15(37).

2. Johnson DC, Bhatta MP, Gurung S, Aryal S, Lhaki P, et al. (2014) Knowledge and awareness of Human Papilloma Virus (HPV), Cervical Cancer and HPV vaccine among women in two distinct Nepali communities. Asian Pacific journal of cancer prevention 15(19): 8287-8293.

3. Kim K, Kim B, Choi E, Song Y, Han HR (2015) Knowledge perceptions and decision making about Human Papilloma Virus vaccination among Korean American women: A focus group study. Women's health issues 25(2): 112-119.

4. Kose D, Erkorkmaz U, Cinar N, Altinkaynak S (2014) Mothers' knowledge and attitudes about HPV vaccination to prevent Cervical Cancer. Asian Pacific journal of cancer prevention 15(17): 7263-7266.

5. Hussain SMA (2013) Comprehensive update on cancer scenario of Bangladesh. South Asian journal of cancer 2(4): 279-284.

6. Papri FS, Khanam Z, Islam F, Hakim M (2015) Knowledge and awareness about risk factors of Cervical Cancer, its screening and vaccination among the women attending Chittagong Medical College Hospital. Chattagram Maa-OShishu hospital medical college journal 14(2): 57-60.

7. Farnandez ME, Le YL, Espada NF, Calo WA, Savas LS, et al. (2014) Knowledge, attitudes and beliefs about Human Papilloma Virus (HPV) vaccination among Puerto Rican mothers and daughters: a qualitative study. Prev Chronic Dis 11: E212.

8. Banik U, Ahmed MSU, Bhattacharjee P, Adhikary AK, Rahman Z (2013) High risk Human Papilloma Virus type 16 and 18 infection in the cervical lesions of women with epithelial cell abnormality in pap smear: A cytohistomorphologic association in Bangladeshi women. Cyto Journal 10: 14.

9. Haesebaert J, Magnin DL, Kalecinski, Barone G, Jacquard AC, et al. (2012) French women's knowledge and attitudes towards Cervical Cancer prevention and the acceptability of HPV vaccination among those with 1418year old daughters: a quantitative-qualitative study. BioMed Central Public Health 12(1034): 2-10.

10. Ahmed SA, Sabitu K, Idris SH, Ahmed R (2013) Knowledge, attitude and practice of Cervical Cancer screening among market women in Zaria, Nigeria. Nigeria Medical Journal 54(5): 316-319. 
11. Bulbul S, Yalcin S, Araz NC (2013) Thoughts of mothers with children 0-15 years of age about Cervical Cancer and HPV vaccination in Anatolia. Turkish J pediatric Dis 2: 73-78.

12. Marlow LAV, Waller J, Wardle J (2007) Parental attitudes to pre-pubertal HPV vaccination. Vaccine 25(11): 19451952.

13. Ozan H, Demir BC, Atik Y (2011) Detecting the knowledge level of patients who admitted to obstetrics and gynecology departments about Human Papilloma Virus and HPV vaccination. Urology university J Fac Medicine 37: 145-148.

14. Thompson SVLS, Arnold LD, Notaro SR (2011) African American parents' attitudes towards HPV vaccination. Ethn Dis 21(3): 335-341.

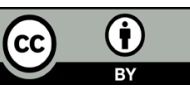

